\title{
When God Spoke Greek. The Septuagint and the Making of the Christian Bible
}

Oxford University Press, New York, 2013, 216 págs.

ISBN 978-0-19-978172-0

por Lidia Raquel Miranda

[CONICET / UNLPam mirandaferrari@cpenet.com.ar]

C

texto When God Spoke Greek. The Septuagint and the Making of the Christian Bible, de Timothy Michael Law, parte de la idea de que es imposible leer la Septuaginta junto con la Biblia hebrea y concluir que sus contenidos teológicos son idénticos. Aun cuando la fuente hebrea de la Biblia de los Setenta haya sido la misma que la del texto hebreo y las divergencias sean atribuibles a la traducción, el texto griego comporta desarrollos teológicos propios acerca de la escatología, el mesianismo, las profecías y la santidad de Dios, entre otros, que lo separan de la Biblia hebrea. Frente a esta constatación, el objetivo del libro es relativizar las especulaciones que durante mucho tiempo, e incluso en la actualidad, han asignado una posición ancilar a la Septuaginta respecto de la Biblia hebrea y han considerado a esta última como el "genuino Antiguo Testamento".

La publicación se organiza en 14 (catorce) capítulos, el apartado de
Notas de cada uno de ellos, un listado de bibliografía (Further Reading) que no es, según indica el autor, exhaustivo sino más bien orientativo, y un índice temático final.

Existen cuatro razones fundamentales que justifican la iniciativa de ocuparse de la historia y características de la traducción griega del Antiguo Testamento.

En primer lugar, la Septuaginta arroja luz respecto del desarrollo del pensamiento judío entre el tercer milenio a.C. y el siglo IV d.C. En efecto, el texto resulta de gran valor para comprender el judaísmo helenista, el Nuevo Testamento y el cristianismo temprano: tal como afirma Law, el Nuevo Testamento no puede leerse sin considerar el contexto del judaísmo helenista y este se vuelve mucho más aprehensible al estudiar la Septuaginta.

Por otro lado, si bien las traducciones del Antiguo Testamento de casi todas las versiones modernas en inglés, consideradas puntualmente 
por el autor, están basadas en la Biblia hebrea, la forma de escritura usada por los autores del Nuevo Testamento y la primera Iglesia fue con mayor frecuencia la de la Septuaginta. La creación del concepto de Antiguo Testamento por los autores neotestamentarios y el primer cristianismo obedeció casi enteramente a la disponibilidad de estas escrituras en lengua helénica para un mundo mediterráneo que era predominantemente griego. Como sabemos, que en el siglo I una religión proclamara su antigüedad le garantizaba respeto, por ello los nuevos escritos en griego sobre la vida y el ministerio de Jesús y sobre los primeros años de la Iglesia necesitaban ser la continuación de una historia más antigua: el cristianismo no era nuevo en la escena, querían decir sus mentores, sino que tenía sus raíces en los días de los patriarcas. Así, las escrituras judías escritas en griego permitieron a los primeros cristianos reclamar una herencia histórica. Los cristianos podrían haber proclamado su mensaje igualmente si hubieran permanecido en hebreo y arameo pero se dieron cuenta de que el potencial para que la expansión de la Iglesia creciera exponencialmente radicaba en que la antigua historia de Israel fuera accesible en la lengua del mundo mediterráneo de aquellos días, el griego.

Como tercer alegato se indica el hecho de que los primeros cristianos no solo emplearon la Septuaginta sino que también su teología estaba explícitamente formada por ella y no por la Biblia hebrea. El uso de las escritu- ras griegas continuó luego de la primera centuria, y la primitiva Iglesia desarrolló sus principales doctrinas a través del contacto con la Septuaginta, es decir que, en la mayor parte del período formativo de la teología cristiana, los pensamientos de la Iglesia fueron moldeados por la Septuaginta. Ninguna de estas afirmaciones sería significativa si la Septuaginta fuera una mera traducción de las escrituras hebreas, pero la Septuaginta en muchos pasajes contiene un mensaje en gran medida diferente, y no solo porque los traductores crearon nuevos significados en su traducción sino también por algunas otras importantes razones, que constituyen el cuarto fundamento del autor: la Biblia de los Setenta a menudo preserva un testimonio de una forma alternativa, y a veces más antigua, del texto hebreo. La Biblia hebrea en las ediciones modernas no es la forma más antigua en esa lengua, y en realidad no es un texto singular, sino una amalgama de similar pensamiento pero no de idénticas fuentes. En muchos casos, la Septuaginta provee el único acceso a la fuente más lejana, porque las modernas ediciones del texto hebreo de la Biblia se basan en un texto que fue más o menos establecido en el siglo II de la era cristiana $y$, mientras las tradiciones textuales para algunos de los libros se remontan al siglo III y posiblemente aún al $\mathrm{V}$ antes de Cristo, su texto es de solamente una de las tradiciones conocidas y usadas por los lectores de la escritura en los tiempos antiguos. Hoy es indiscutible que la Biblia hebrea es parte de una 
diferente tradición de los textos bíblicos conocidos en otras fuentes. Y, en este sentido, el conocimiento de la Septuaginta realmente ha trastocado el cuadro simple con el cual hemos estado familiarizados durante mucho tiempo, tanto en la cultura popular como en la académica.

Todos estos temas son presentados en el primer capítulo, Why This Book?, sección que se completa con una explicación sobre los contextos de la religión hebrea y la traducción de la Biblia al griego y pone especial énfasis en la historia de la diversidad de textos bíblicos, generalmente desconocida por un lector no especialista, de la que participan la Septuaginta, los famosos Rollos del Mar Muerto, los textos apócrifos, etc.

El segundo capítulo, When the World Became Greek, es marcadamente histórico pues presenta los hechos y las personalidades que caracterizaron el mundo mediterráneo de la Antigüedad en la época previa al surgimiento del cristianismo.

Was There a Bible before the Bible?, se pregunta Law en el tercer capítulo. Para responder al interrogante, explica que no hay dudas acerca de que el texto fuente de la Biblia hebrea que conocemos es muy antiguo; sin embargo, los Rollos del Mar Muerto, junto con una renovada apreciación de la Septuaginta, obligan hoy a adoptar una nueva perspectiva: si bien los escribas masoréticos medievales preservaron una antigua tradición, trasmitieron solo una tradición escrituraria de entre un número de divergentes posibilidades que exis- tían antes del siglo II d. C. El período más temprano se caracterizaba por la pluralidad, no la uniformidad de tradiciones. Sostiene el autor que no hay nada equivocado en afirmar que la Biblia hebrea de las ediciones actuales refleja una antigua tradición que alcanza al menos al tercer siglo a. C., y tal vez más, pero es necesario tener en cuenta que esa es solo una parte de la historia. En realidad, existen tres testimonios para establecer la historia de la Biblia: el texto masorético, el Pentateuco Samaritano y la Septuaginta.

Una de las más relevantes contribuciones de los masoretas, escribas judíos de la Edad Media, a la historia de la Biblia hebrea fue la introducción de vocales en el texto consonántico para clarificar la tradición de lectura. Esto significó un filtro semántico pues la antigua tradición quedó mediatizada por la lectura medieval. Por otro lado, es necesario aclarar que el texto que los masoretas eligieron para editar posiblemente fuera el que tenían disponible en su momento y no necesariamente el más antiguo.

El Pentateuco Samaritano no es una traducción sino una versión de la Torah hebrea, valorable por su testimonio de las diferencias en la ideología samaritana - en rivalidad con el liderazgo centralizado de Jerusalén-; además contiene abundantes acuerdos con la Septuaginta, en discrepancia con la versión masorética.

Los manuscritos del Mar Muerto vindican la hipótesis de que la Septuaginta fue traducida a partir de textos hebreos alternativos. Law des- 
taca que el estudio conjunto de los manuscritos bíblicos de Qumran, la Septuaginta y la Biblia hebrea arroja luz a un período de pluralidad textual entre los siglos III a. C. y II d. C. y que los manuscritos del desierto de Judea prueban que la Biblia hebrea es solo una de las muchas tradiciones de textos escriturales usados antes de la segunda centuria. Insiste por ello en la necesidad de ser cuidadosos para no distorsionar la evidencia al mirar ese período a través de las lentes de nuestro presente conocimiento del estatus autoritativo ganado por la Biblia hebrea posteriormente.

Si bien la traducción no era una actividad desconocida en el mundo antiguo, ninguna de las traducciones previas había tenido relación formal con una religión, mucho menos con la de un pueblo no dominante. El volumen del texto para traducir también debió haber sido intimidante. Justamente de la traducción y sus traductores se ocupa el capítulo 4, The First Bible Translators. Law considera que la traducción fue el modo de sobrevivir del judaísmo fuera de Judea.

No existen fuentes directas que puedan ofrecer un cuadro de los orígenes de la traducción o una evaluación de la traducción misma. Solo se cuenta con una fuente literaria, La carta de Aristeas a Filócrates, que tiene importancia porque aduce ser un testigo del suceso y concede autoridad a la Septuaginta al presentarlo como un texto revelado.

La traducción de las escrituras judías al griego fue realizada en Egipto. El estilo indica que los traductores tenían una educación básica, pero su entrenamiento no debía ser más que elemental. Todas las evidencias parecen indicar que eran judíos helenizados en Alejandría, moderadamente educados. Desafortunadamente, la certeza no es total.

El capítulo se concentra principalmente en tratar de esclarecer por qué se produjo la Septuaginta, para lo cual presenta las posibles explicaciones: 1) aun cuando la Carta de Aristeas sea un relato ficcional, el interés real por la traducción podría ser un elemento histórico; 2) la traducción pudo haberse hecho con propósitos litúrgicos para permitir a los judíos helenizados continuar sus tradiciones religiosas dado que su competencia en hebreo estaba disminuyendo; 3) surgida en un contexto escolar, en relación con su par hebrea, la traducción no fue un texto autónomo, condición que habría adquirido en su posterior recepción; 4) la traducción pudo deberse a la necesidad de dotar a las escrituras hebreas del aire del momento a través de la lengua más usada en esos días.

En el capítulo 5, Gog and His NotSo-Merry Grasshoppers, el texto se refiere al hecho de que, en los tiempos de la traducción, los libros eran solamente una colección de escritos con límites indefinidos. En esta sección se explica que el canon de la Biblia hebrea no finalizó hasta la segunda centuria de la era cristiana, por ello no es enteramente satisfactorio focalizarse en estos libros y/o separarlos de los apócrifos, como el autor ha hecho en el capítulo. Sin embargo, justifica su elección metodológica en que, como 
muchos judíos y cristianos conciben la Biblia hebrea/Antiguo Testamento de esa manera, ha hecho un tour a través de los libros en la Septuaginta que son traducciones del hebreo y del arameo, que serían formalizados y canonizados en la Biblia hebrea alrededor del siglo II. De los textos apócrifos, entonces, Law se ocupa en el capítulo 6, denominado Bird Droppings, Stoned Elephants, and Exploding Dragons. Y en el capítulo 7, E Pluribus Unum, el foco se halla puesto en el texto hebreo del siglo II, época de eclipse de la circulación plural de tradiciones y textos característica en la centuria anterior.

El uso directo de la lengua no fue la única manera en que la Septuaginta influyó en el Nuevo Testamento, aunque las formas alusivas son más difíciles de probar, como hace el mismo Law a través de la presentación de numerosos ejemplos en el capítulo 8, The Septuagint behind the New Testament. El impacto que la Septuaginta tuvo en el lenguaje y en la teología del Nuevo Testamento queda claro en los casos analizados, pero el autor propone, además, prestar atención a las explícitas citas del Antiguo Testamento en el Nuevo desde el Evangelio de Mateo hasta el Apocalipsis, tarea que aparece en el siguiente apartado, The Septuagint in the New Testament. Dicho capítulo contempla el entorno lingüístico de los autores de los Evangelios, en los que se advierte la combinación de material narrativo acerca de la vida y enseñanzas de Jesús y sus propias versiones e interpretaciones de estas palabras. Concluye Law que, más allá de que usaran o recordaran el texto hebreo - principalmente el autor de Mateo-, los escritores neotestamentarios debieron usar una revisión griega: el capítulo demuestra que la mayoría, sino todas, las citas en el Nuevo Testamento no son estrictamente dependientes del texto hebreo, y en esos casos aparecen cercanos a una versión en griego. Lo más destacable es que muchas citas fueron tomadas de la Septuaginta para ofrecer un desarrollo teológico que no hubiera sido posible si se hubiera citado el texto hebreo. Otra conclusión de esta parte es que el estado del texto del Antiguo Testamento en el siglo I estaba todavía en flujo, circunstancia que, evidentemente, no perturbó a los autores del Nuevo Testamento.

Habiendo examinado el uso de las escrituras judías en el Nuevo Testamento, el capítulo 10, The New Old Testament, se concentra en cómo los primeros cristianos leyeron el Antiguo Testamento en la segunda centuria y posteriormente. Los primeros pensadores cristianos tenían otros dos problemas en adición al desarrollo de la lista de libros para configurar el Antiguo Testamento: tenían que decidir cómo justificar el uso de escritos judíos como escritura cristiana y, no más allá de la segunda centuria, demuestran una cierta disconformidad con las diferencias entre la Septuaginta y las escrituras judías que eran confirmadas en algunos círculos judíos. Los cristianos pronto se dieron cuenta de que estaban teologizando sobre la base de textos escriturales que no eran usados por los judíos y por ello la 
Nueva Israel, es decir la Iglesia, debió dirigir su atención a la discrepancia. Si bien algunos cristianos sostenían la superioridad de la Biblia hebrea, la única que alguna vez había existido, la mayoría creía que la Septuaginta era la nueva palabra de Dios para la Iglesia, un texto divinamente inspirado que Dios había entregado para llevar el mensaje de la cristiandad al mundo y no les preocupaba saber cómo la Septuaginta coincidía con el texto hebreo. Sin considerar el tema de la traducción, para el común de la gente era que, así como Dios hizo con los judíos en hebreo y arameo, ahora había hablado en griego para la Iglesia. Esta creencia, derivada en parte de la actitud de Filón de Alejandría hacia la Septuaginta, desarrolló luego entre los cristianos la creencia de que Dios llevaba un nuevo mensaje en griego para preparar al mundo para el evangelio cristiano. Los judíos habían perdido su oportunidad.

Así, los cristianos empezaron a establecer su propio texto, evitando en lo posible el uso de testimonios sueltos. Una de las razones que tuvieron para adoptar un texto establecido fue la invención del códice, que en la segunda centuria facilitó la emergencia de la Biblia. Las implicaciones para la historia de la cultura, como sabemos, fueron enormes: el libro era más portable, más fácil de leer que los rollos y menos costoso; sin embargo, la evidencia sugiere que los cristianos adoptaron el códice más bien por razones socio-religiosas, ya que querían distinguir sus propios libros de los de los judíos y de la literatura pagana.
El capítulo 11, titulado God's Word for the Church, se focaliza en los trabajos de Filón, Flavio Josefo, Pablo, Eusebio y Epifanio, en relación con otras traducciones, como la de Aquila, Símaco y Teodocio. Dichos autores antiguos señalaron la superioridad de la Septuaginta y sus pensamientos permiten advertir su influencia en la preparación del Nuevo Testamento. También Law afirma que la Septuginta está en el corazón de la temprana Iglesia y que el Antiguo Testamento en griego fue de capital importancia en la formación del pensamiento cristiano: salvo un pequeño número en la Iglesia siríaca, todo cristiano que leía u oía la Biblia en las primeras centurias de la era cristiana lo hacía de la traducción de la Septuaginta o de la versión latina que apareció. Era el Antiguo Testamento cristiano.

The Man of Steel and the Man Who Worshipped the Sun es el capítulo siguiente, que se refiere a la influencia de la Hexapla de Orígenes en la historia de la Biblia de los Setenta: para Law, esta obra fue el comienzo del fin de la Septuaginta en la Iglesia. En el capítulo 13, The Man with the Burning Hand versus the Man with the Honeyed Sword, se ocupa el libro de Jerónimo y su posición en contra de la Septuaginta. Varias páginas se dedican al primer gran debate, entre Agustín y Jerónimo, conflicto que debe ser leído en atención a los lugares en los que cada uno de ellos trabajó: Agustín, el gran campeón de la Septuaginta en la Iglesia, estaba en el Norte de África, lejos del centro de acción en la polémica judío-cristiana 
acerca de la naturaleza del texto del Antiguo Testamento; mientras que Jerónimo estaba justo en el medio del debate en Belén.

Por último, el capítulo 14 es $A$ Postscript que opera como un balance y síntesis de los aspectos más relevantes abordados a lo largo de When God Spoke Greek. The Septuagint and the Making of the Christian Bible: 1) los autores del Nuevo Testamento casi siempre usaban la Septuaginta para acceder a la escritura judía que a menudo citaban; 2) ejemplos de los Evangelios y de las cartas de Pablo demuestran que la Septuaginta tuvo un profundo impacto en el desarrollo del pensamiento neotestamentario; 3) a la luz de la probada diversidad de las formas hebrea y griega en el período antiguo, en el tiempo del Nuevo Testamento y en la era patrística, se pregunta el autor por qué el rol de la Septuaginta ha sido tan empequeñecido en el pensamiento cristiano moderno.

Muchos son los puntos destacados que hemos soslayado en esta recensión para no abrumar al lector $y$, en todo caso, propiciar su propia lectura. Sin embargo, la exposición precedente es una buena muestra de los alcances de la publicación. En efecto, el libro hace hincapié en el giro que la historia bíblica da con el estudio de los libros de la Septuaginta, ya que permite descubrir que la Biblia griega forma parte de la tendencia de diversidad textual propia de su época y que la Biblia hebrea, familiar al lector gracias a las traducciones al inglés, difiere bastante de la versión griega.
También este estudio permite comprobar que los textos apócrifos son una parte importante de la historia bíblica, no solo porque se trata de una colección de libros conocida por más de un billón de cristianos por fuera de la tradición protestante sino también porque influyó en los escritores del Nuevo Testamento y en la Iglesia temprana.

When God Spoke Greek. The Septuagint and the Making of the Christian Bible es una obra que tiene la virtud de concitar la atención tanto de un lector especializado como la de un público general. A ello contribuye, sin duda, el estilo utilizado en la redacción pero sobre todo el modo de discutir los distintos temas, de clarificarlos con abundantes ejemplos - en especial los de tipo comparativo entre la versión griega y la hebrea del Antiguo Testamento a través de traducciones al inglés - y de promover la consulta de obras más eruditas. Una de las contribuciones más relevantes para un lector común es el hecho de diferenciar las nociones de 'escrituras' o 'textos escriturales' de las de 'Biblia' y 'canon', con la cual el autor logra problematizar la visión más generalizada del texto y presentar un panorama ilustrativo de la cultura textual que dio origen al pensamiento cristiano. Para el receptor especialista, el texto resulta una completa síntesis del proceso de génesis, traducción y recepción de los escritos judíos, que puede ser utilizada con buenos resultados en la transposición didáctica. Asimismo, los debates antiguos en torno a la traducción griega así como 
las diferentes posturas existentes hoy en la literatura científica, claramente expuestos por el autor, ponen sobre el tapete no solo la necesidad de profundizar el estudio de la Septuaginta sino también de estar atentos a las repercusiones de su historia y su teología en el marco del pensamiento cristiano de todos los tiempos. Como carencia puede señalarse el hecho de que la obra no incluya ejemplos en lengua original; sin embargo, creemos que eso ha sido una elección deliberada del autor para facilitar el acercamiento al tema por parte del lector no especializado.

\section{CRESPO, María Inés y MARTIGNONE, Hernán (comps.)}

\section{“'A quién, otra vez, he de persuadir?”. Intercambios discursivos entre hombres y dioses en la épica y la tragedia griegas}

Editorial de la Facultad de Filosofía y Letras, Universidad de Buenos Aires, 2013, 266 págs. ISBN 978-987-3617-09-6

por Paola Druille

[UNLPam / CONICET paodruille @gmail.com]

$\mathrm{L}$ a literatura griega del período arcaico y clásico se caracteriza por los complejos intercambios discursivos entre lo humano y lo divino. Los hombres imploran a la divinidad de modos diversos y esperan que los dioses respondan a sus súplicas. Este intercambio en forma discursiva es trabajado en los distintos capítulos compilados por la investigadora y Doctora en Letras Clásicas, María Inés Crespo, y por el Profesor y Licenciado en Letras, Hernán Martignone, en la edición que se titula " $\mathrm{¿} A$ quién, otra vez, he de persuadir?" Intercambios discursivos entre hombres $y$ dioses en la épica y la tragedia griegas. Los capítulos compilados son el resultado del trabajo de investigación realizado por los integrantes del proyecto denominado "Caracterización y función de los intercambios discursivos entre figuras divinas y humanas en los géneros épico y trágico: tradición e innovación", financiado por la Secretaría de Ciencia y Técnica de la Universidad de Buenos Aires (UBACyT F-815, 2006-2007, y 2008-2010). Cada trabajo propone un abordaje interdisciplinario y transdisciplinario de los estudios clásicos, y plantea una nueva aproximación a los textos de la Antigüedad griega, cuyos contenidos son adaptados a los modelos teóricos provenientes de los estudios lingüísticos y literarios contemporáneos. 